\title{
Faculty Development Trends in Medical Education: a Review
}

\author{
Prashanth Hegde ${ }^{1}$
}

\section{Background}

\section{Current trends in medical education}

Change is the way of life. We live in a momentous time and the future calls for new paths and fundamental changes. This statement is apt in medical education as well. The major trends in this context consist of the aspects and driving forces underlying the changes that occur. This includes demographic transformations, shortage of work forces, the emphasis on clinical quality and patient safety, financial challenges, the pursuit of excellence and the pressure to adopt information technology. In addition, the structure of medical schools has been influenced by an exponential increase in medical knowledge and changes in healthcare delivery, patient expectations, and the needs and requirements related to medical students. To keep pace with changes, quality improvement and innovations in medical education are now being addressed globally by many important associations and organizations.

World Federation for Medical Education (WFME), Institute for International Medical Education (IIME), Australian Medical Association (AMA), Asia Pacific Medical Education Conference (APMEC), Association for Medical Education in Europe (AMEE), Canadian Association for Medical Education (CAME), Associations for the Study of Medical Education (ASME), Association of American Medical Colleges (AAMC), Accreditation Council for Graduate Medical Education (ACGME) are a few (Ahmady, 2009).

\footnotetext{
${ }^{1}$ Administrative Head, Department of Obstetrics \&

Gynaecology, Gulf Medical University - AJMAN, UAE

Corresponding author:

Dr. Prashanth Hegde, Administrative Head

Department of Obstetrics \& Gynaecology

Gulf Medical University - AJMAN, UAE

E-mail: drprashanthhegde@yahoo.com
}

It is clear that a new vision is needed to address the challenges of medical education. It is in this context literature was reviewed on trends in faculty development in medical education.

There is also a need for a new model to shape the minds and hearts of future healthcare professionals. This requires adoption of new curricula, novel pedagogies and innovative forms of assessment, and of course well developed faculty members since these individuals represent one of the most important assets of an academic institution (Whitcomb, 2003).

\section{Defining faculty development}

Faculty development in the literature is defined in different ways. Different terms such as staff development, faculty development, academic development, educational development and instructional development are used in higher educational systems synonymously or interchangeably in different parts of the world. Although these terms have slightly different meanings they have a common core in that they refer to work conducted by developers to study and enhance the professional performance of university academicians. The ultimate goal is to teach faculty members the skills relevant to their institutional and faculty position and to sustain their vitality both now and in the future.

The definition of faculty development has evolved and been expanded over the past few decades and various definitions have been used in higher education. In 1975, Gaff referred to faculty development as "activities that help teachers improve their instructional skills, design better curricula, and /or improve the organizational climate for education" (Gaff et al., 1978). Centra described it as "the broad range of activities used by institutions to renew or assist faculty members in undertaking their expected roles" (Centra, 1976; Centra,1978). A decade later, Bland and Stritter broadened 
the definition by mentioning a shift in the focus of faculty development from the individual teacher to the needs of departments and institutions. This broader and more inclusive definition by Bland as defined below has generally been the most accepted by the medical education community (Bland et al., 1990).

\section{Definition}

Faculty development is a planned program designed to prepare institutions and faculty members for their various roles and to improve an individual's knowledge and skills in the areas of teaching, research and administration (Bland et al., 1990).

"The personal and professional development of teachers, clinicians, researchers and administrators to meet the goals, vision and mission of the institution in terms of its social and moral responsibility to the communities it serves" is another comprehensive definition of faculty development at the institutional level (Mc Lean et al., 2008).

\section{Factors determining the trend}

\section{The importance of faculty development}

Over the last few years, faculty development has become a very popular term in higher education in general and medical education in particular. George Miller said, "It is curious that so many of our most important responsibilities are undertaken without significant preparation. Marriage, parenthood and teaching (in medical schools) are probably most ubiquitous illustrations" (Abeykoon, 2007). It has been emphasized that medical school faculty members are trained in the roles of their discipline (e.g., clinical duties and healthcare delivery) but are essentially not taught to succeed as educators, researchers, scholarly writers or administrators. In most cases, they do not learn academic skills related to curriculum development, instructions, evaluation, research, scientific production or administration. Very few faculty members are trained to manage their roles as teachers (Steinert, 2005). Teachers of medical students rarely receive formal training in teaching, education, or assessment of learners. Most faculty who teach are unaware of the literature on cognitive psychology, adult learning and the development of mastery and expertise. New faculty usually relies on imitating the senior faculty, trial and error or even luck for obtaining educational skills.
The idea is that if you want to change medicine, you have to change those who teach medicine, and this can be accomplished with specific educational strategies including faculty development.

Faculty members constitute the major component of medical education, not only due to their direct influence on the teaching and learning process, but also because they play an important role in shaping the curriculum and environment of teaching.

Medical education has evolved to become a discipline in its own right. With demands on medical faculties to be socially responsible and accountable, there is now increasing pressure for the professionalization of teaching practice. Developing a cadre of professional and competent teachers, educators, researchers and leaders for their new roles and responsibilities in medical education requires faculty development (Mc Lean et al., 2008).

\section{Need for faculty development in medical education}

It is necessary for the present day teacher to be aware of and become part of far reaching changes that are taking place in medical education. The changes are: shift from conventional role of teacher, changes in learning styles, innovative curriculum models and changes in assessment philosophy, methods and tools (Srinivas \& Adkoli, 2009).

There is an unprecedented growth of medical institutions occurring in the past two decades resulting in shortage of medical teachers (Singh et al., 2008). The number of medical schools in India has doubled in the last 20 years (Supe \& Burdick, 2006) and there is a universal need for faculty development in medical education (Amin et al., 2009).

Multiple roles for teachers: The teacher in the present scenario is expected to play multiple roles such as facilitator, curriculum and course planner, resource developer, mentor, student assessor and program evaluator.

Changing Learning methods: Medical students need to be effective lifelong learners in order to continue to develop personally and practice professionally. Application of adult learning principles, student autonomy, self-learning, experiential learning, reflective learning, computer assisted learning, distance learning, e- learning, use of skill learning laboratories are some of the areas requiring expertise, 
which are not readily available with most teachers. To deal with a new scenario, medical teachers are obliged to keep themselves updated through faculty development.

Innovative curriculum models: Changing trends in medical education globally resulted in more innovative curricula such as the 'Problem Based Curriculum' (PBL), 'Integrated Curriculum', 'Cell Biology Curriculum', and also the 'Competency Based Curriculum' (Dath \& lobst, 2010). Shifting to a new curriculum requires skills and competence that cannot be taken for granted.

New Assessment methods and tools: The traditional methods of assessment have been challenged due to dissatisfaction over their validity and reliability. Several new methods and tools such as OSCE \& OSPE (Objective Structured Clinical/Practical Examination), OSLER (Objective Structured Long Examination Record), Mini CEX (Mini Case Evaluation Exercise), CbD (Case based Discussion), DOPs (Direct Observation of Procedures) are now available, the use of which requires special training.

Shortage of medical teachers: Developing Asian countries such as India have seen an exponential growth in medical schools for the past six decades. There is shortage of about $20-30 \%$ teachers in medical colleges (Ananthakrishnan, 2007). The future challenge therefore, lies in how best to achieve capacity building of teachers in a short span of time.

\section{Medical education and market forces}

Current healthcare delivery and finance systems are threatening medical education. Medical education costs money while clinical care and research generate income. Investments in research and privatization of healthcare have relegated teaching of medical students to a secondary activity. The frustration levels among faculty who joined universities to teach medical students and be part of an environment that valued the learning process are rising. The rewards and recognition for research and patient care are substantive while those for teaching and education are much fewer.

We must realize that teaching medical students is central to the mission of medical schools. It is medical education that distinguishes a medical school from a research institute, clinic or hospital (Goudar et al., 2003).

\section{Internationalization of Medical Education}

Internationalization is one of the most important forces in higher education today. It presents a powerful challenge for medical schools. Among the factors that encourage internationalization are globalization of healthcare delivery, improved communication channels, competitiveness and commercialization (Harden, 2006).

\section{Nature of the trend}

Improving teaching in medical education is not a new concept. It was seriously discussed by pioneers such as Miller and Abrahamson as early as the 1950's (Simpson \& Bland, 2002). By 2005, a significant number of medical school faculty participated in teaching improvement methods. Yet the value of faculty development has evolved rather slowly (Boonyasai et al., 2007). Changing trends in regulatory reforms and physician licensure may partly havecontributed (Dower et al.,1998).

\section{Faculty Development movement}

WHO initiative: An expert committee of the World Health Organization (WHO) in 1965 brought out a report on the "Training of teachers of medical schools with special regard to developing countries". With this aim and as a part of global initiative for teacher training, WHO designated two centres for Medical Educational Development in the US in 1969. These centres trained educational specialists and leaders for the six Regional Teacher Training Centres (RTTCs) that were established in South East Asian Region. These RTTCs with support from IRTTCs trained national level educational leaders for establishing National Teacher Training Centres (NTTC). The major aim of NTTCs was to train teachers from medical colleges in their respective countries who would establish medical education units in their colleges.

FAIMER initiatives (2001): The Foundation for Advancement of International Medical Education and Research (FAIMER), in Philadelphia, USA supports faculty development through two-year part time fellowship program designed to develop managerial and leadership skills, in order to promote changes in medical education through networking.

In a systematic review of faculty development initiatives conducted in Canada over 22 years it was observed that these activities appear highly valued by participants, who also report changes in learning and behaviour (Steinert, 2005). 
A recent international web-based survey of 806 of the 2200 members of the Association for Medical Education in Europe focused on the perceived needs of medical educators from 76 countries. The United Kingdom and the United States had the highest representation among the respondents (24\% and $10 \%$ respectively) (Huwendiek et al., 2007).

\section{Advantages}

All academic generalists have scholarly interests. One advantage of the Faculty Development Program is the exposure of teachers to the advice and mentoring from senior faculty and other experts. Another advantage is setting aside time and working together as a group in faculty development sessions. This aspect of the program has contributed importantly to the success of faculty members as they pursue their professional development in academic medicine. Numerous projects begun during the year of faculty development have led to successful publications, workshops at national meetings and/or teaching programs of value to the field of medicine.

Faculty members can take advantage of professional development opportunities to acquire new skills and knowledge in teaching, research, or administration. In addition teachers can also get insight about how to learn before stepping in to teaching as a profession in medical education. A faculty member who is interested in education can build a network of colleagues who feel the same about the change through faculty development and convince decision makers of the need for change (Kent, 2007). Studies have shown that offering a menu of faculty development opportunities and combining with continuing medical education objectives or competencies increases participation.

The greatest advantage of faculty development is that it indirectly improves the healthcare. Training better doctors of tomorrow solely depends upon the availability of trained and experienced medical educators. Faculty development facilitates this process. This indirectly reflects the quality of healthcare.

\section{Disadvantages}

Imparting faculty development programmes can in no way be considered a demerit in a strict sense. However some perceptions portray faculty development in a negative way making it a disadvantage.
At the level of administrators, it is sometimes perceived that each hour that a medical school faculty member devotes to teaching represents an hour of lost clinical revenue. Research too, offers opportunities to generate additional income through extramural funding and partnerships with industry. Devoting more time to education however usually generates no immediate income but definitely has positive implications in the long run. Faculty taking time out of their regular teaching commitments for faculty development programmes may be a potential short term disadvantage. However this may not be considered a disadvantage in the long run.

\section{Pitfalls in implementation}

\section{Challenges and Obstacles to Faculty development}

There are some factors which are considered as challenges and obstacles that are expected to influence the success of faculty development programs. To name a few, for example, balancing individual and organizational resources and dealing with inadequacy of managerial and/or organizational support, resistance to change, and lack of follow-up activities.

The main challenge in medical education identified by the survey respondents in Europe by the Association of Medical Education in Europe were lack of academic recognition (40\%), funding (36\%), faculty development $(24 \%)$, time for medical education issues $(22 \%)$, and institutional support (21\%) (Huwendiek et al., 2007).

There are internal and external driving forces in Iranian medical schools that challenge the traditional academic triad of teaching, research and service. Peculiar to Iran are the challenges caused by the integration of healthcare and medical education, which consist of multiple faculty roles that complicate the professional responsibility.

In developing countries attracting younger professionals to teaching is a real challenge. Most seem to be having other priorities in this globalized, market-oriented world with an inclination for rapid monetary gains. Clinicians try to place themselves in more rewarding corporate hospitals as compared to poorly paid teaching hospital jobs.

The other possible pitfall relates to the timing of faculty development activities. If undertaken too early, when the new faculty member joins, 
it may be inappropriate as the young faculty member is more concerned with mastering the discipline. If done too late, bad habits may already have set in, and are difficult to get rid of.

Medical educational research has serious constraints in developing countries such as lack of financial resources, lack of collaboration and commitment (Majumder, 2004), lack of infrastructure, support staff, time constraint and preoccupation with patient care (Adkoli, 2009).

\section{Guidelines for implementation}

To respond appropriately to the rapidly emerging changes in medicine, medical educators need to change medical education. We can do this by changing the people who teach medicine - at all levels - and change what they teach, how they teach, and how they do research in medical education. To accomplish this, faculty development must change. The ideal modern and future faculty development concept was conceptualized in a conference entitled "A 2020 Vision of Faculty Development across the Medical Education Continuum" held at Baylor College of Medicine between February 26 and 28, 2010. The objective was to develop recommendations for training faculty who prepare physicians to meet the nation's evolving health care needs. Quality faculty development must be made available to all who teach medicine. Areas of faculty development that present unique challenges and will require a concerted effort to implement include new educational technologies, bioinformatics, and new information concerning the biology of learning (Searle et al., 2011). Incorporating the notions of SDL, peer mentoring and work based learning is also vital (Steinert, 2011).

\section{Funding for and Recognition of Faculty Development}

Funding requirements would vary, depending on the level of training and competence necessary at each teaching level. One way to economically provide teacher training is to develop Web-based teaching modules. This is especially important for those institutions that have few faculty development offerings.

\section{Bringing about attitudinal change among faculty}

The most difficult part of faculty development is changing the attitudes of faculty members towards faculty development. Motivating teachers and reinforcing them about the beneficial significant positive effects of faculty development program on medical teachers' competencies as reported by Ebrahimi \& Kojuri (2012) is one of the ways out. This could also be accomplished by providing academic recognition to the teachers for their contribution to teaching. Otherwise, teaching will be overtaken by the priorities of research and patient care. It is important to encourage and reward teachers who show a flair for teaching and adopt innovative teaching methods.

\section{Communication and Sharing of Materials between Faculty and Institutions}

Establishing connections with other medical organizations and other professions enhances the resource base and also newer ideas. A greater sharing of high quality learning resources is a way forward (Harden \& Hart, 2002). London Deanery has provided a webbased resource for supporting the educational development needs of clinical teachers since 2002. Following a review in 2007, Deanery commissioned a series of new e-learning modules designed as an introduction to clinical teaching (Swanwick, 2008).

\section{International Cooperation and Support for Faculty Development}

Various national and international organizations support research, development and implementation of faculty development / health professional education projects. There must be a global dialogue on improving international health professions education. FAIMER advocates collective exploration and problem-solving, to strive for tangible results from the faculty development activities that will lead to healthier and stronger community of medical teachers for tomorrow.

\section{Acknowledgement}

Special and sincere thanks to Prof (Dr) Raja C Bandaranayake, Visiting Professor Gulf Medical University UAE for his guidance and inputs in this review.

\section{References}

Abeykoon, P. (2007) Training of Medical Teachers in the South East Asian Region, National Conference on Medical Education AlIMS, New Delhi.

Adkoli, B.V. (2009) Faculty development and medical education units in India: A survey. The National Medical Journal of India, 22, 1, 28-32. 
Ahmady, S. (2009) Faculty development in medical education: A comprehensive approach, Stockholm Sweden, Karolinska Institutet.

Amin, Z., Khoo, H.E., Chong, Y.S., Tan, C.H., Goh, P.S., Samarasekera, D.D., Chan, Y.K. \& Kho, D.R. (2009) A multi-institutional survey on faculty development needs, priorities and preferences in medical education in an Asian medical school, Medical Education Online, 14,16, doi: 10.3885/meo.2009.Res00317.

Ananthakrishnan, N. (2007) Acute Shortage of Teachers in Medical Colleges: Existing problems and possible solutions, The National Medical Journal of India, 20, 1, pp.25-29.

Bland, C.J., Schmitz, C.C., Stritter, F.D., Henry, R.C. \& Aluise, J.J. (1990). Successful faculty in academic medicine: essential skills and how to acquire them. New York, Springer - Verlag.

Boonyasai, R.T., Windish, D.M., Chakraborti, C., Feldman, L.S., Rubin, H.R. \& Bass, E.B. (2007). Effectiveness of teaching quality improvement to clinicians: a systematic review, Journal of the American Medical Association, 298, pp.1023-1027.

Centra, J.A. (1976) Faculty development practices in US colleges and universities, Princeton, Educational Testing services.

Centra, J.A. (1978) Types of faculty development programs, Journal of Higher Education, 49, 2, pp.151-162.

Dath, D. \& lobst, W. (2010) The importance of faculty development in the transition to competency-based medical education, Medical Teacher, 32, 8, pp.683-686.

Dower, C.M, Gragnola, C.M. \& Finocchio, L.J. (1998), Changing nature of physician licensure. Implications for medical education in California; The Western Journal of Medicine,168, 5, pp. 422-427.

Ebrahimi, S. \& Kojuri, J. (2012), Assessing the Impact of Faculty Development Fellowship in Shiraz University of Medical Sciences, Archives of Iranian Medicine, 15, 2, pp. 79 -81.

Gaff, S.S., Festa, C. \& Gaff, J.G. (1978) Faculty Development. In Professional development: $A$ guide to resources, USA, Transaction Publishers: pp.67-77.

Goudar, S.S. \& Kotur, P.F. (2003) Trends in medical education, Indian Journal of Anaesthesia, 47,1, pp.25-29.

Harden, R.M. \& Hart, I.R. (2002) An international virtual medical school (IVIMEDS): The future for medical education? Medical Teacher, 24, 3, pp. $261-267$.
Harden, R.M. (2006) International medical education and future directions: A global perspective, Academic Medicine, 81, 12 (Suppl), S22-S29.

Huwendiek, S., Mennin, S. \& Nikendei, C. (2007) Medical Education after the Flexner report, New England Journal of Medicine, 356, p 90.

Kent, J. (2007); The Family Medicine Curriculum Resource Project: Implications for Faculty Development, Family Medicine, 39,1, pp.50-52.

McLean, M., Cilliers, F. \& Van Wyk, J.M. (2008) Faculty development: yesterday, today and tomorrow, Medical Teacher, 30, 6, pp.555-584.

Majumder, M.A. (2004) Issues and priorities of medical education research in Asia, Annals, Academy of Medicine, Singapore, 33, 2, pp. 257-263.

Searle, N.S., Thibault, G.E. \& Greenberg, S.B. (2011)Faculty development for medical educators: Current barriers \& future directions, Academic Medicine, 86, 4, pp.405-406.

Simpson, D.E. \& Bland, C.J. (2002) Stephen Abrahamson, $\mathrm{PhD}, \mathrm{ScD}$, educationist: a stranger in a kind of paradise, Advances in Health Science Education Theory and Practice, 7, 3, pp.223-234.

Singh, T., Bansal, P. \& Sharma M (2008) A need and necessity for faculty development : the role of medical education units in the Indian context, South East Asian Journal of Medical Education, 2,1, pp.2-6.

Srinivas, D.K. \& Adkoli, B.V. (2009) Faculty development in medical education in India, Al Ameen Journal of Medical Sciences, 2, 1, pp. 613.

Steinert, Y. (2011) Commentary: Faculty development: the road less travelled, Academic Medicine, 86, 4, pp.409-411.

Steinert, Y. (2005) Staff development for clinical teachers, The Clinical Teacher, 2, 2 pp.104110.

Supe, A.N, Burdick W.P. (2006) Challenges and issues of medical education in India, Academic Medicine, 81,12, pp.1076-1080.

Swanwick, T. (2008) See one, do one, then what? Faculty development in postgraduate medical education, Postgraduate Medical Journal, 84 993, pp.339-343.

Whitcomb, M.E. (2003) The medical school's faculty is its most important asset, Academic Medicine, 78, 2, pp.117-118. 